\title{
Comparison of Estimated and Real COVID-19 Cases and Deaths for 45 Days
}

\author{
Hasan Basri Savas ${ }^{1}$, Zafer Cakir ${ }^{2}$, Mehmet Enes Sozen ${ }^{3 *}$
}

${ }^{1}$ Alanya Alaaddin Keykubat University, Medical Faculty, Department of Medical Biochemistry, Turkey

${ }^{2}$ Alanya Alaaddin Keykubat University, Faculty of Education, Department of Mathematics Teaching, Turkey

${ }^{3}$ Alanya Alaaddin Keykubat University, Medical Faculty, Department of Histology and Embryology, Turkey

\section{Correspondence:}

Mehmet Enes Sozen

Address: Alanya Alaaddin Keykubat University, Medical Faculty, Department of Histology and Embryology, Turkey

Email: enes.sozen@alanya.edu.tr

Received: 06.08.2020,

Accepted: 15.10 .2020

https://doi.org/10.29333/jcei/9565

\begin{abstract}
The Coronavirus Disease 2019 (COVID-19) is caused by the new type of coronavirus, severe acute respiratory syndrome coronavirus-2 (SARS-CoV-2), emerged in China at the end of 2019, and spread all over the world in a very short time. The World Health Organization (WHO) declared COVID-19 a global pandemic due to its rapid spread and lack of effective vaccination, immunization and treatment. In this study, we aimed to make a retrospective evaluation of forty-five days of COVID-19 cases and deaths simulated by the modified mathematical model which was previously established and published by us. 30 days and 45 days of COVID-19 cases and deaths which were estimated by our modified mathematical model were compared to the real cases and deaths in Turkey since 15.03.2020. The COVID-19 cases increased to a significant level on 20.03 .2020 in Turkey. The modified mathematical modeling results' estimation accuracy remained above $90 \%$ until 13.04 .2020 . This rate was $78.40 \%$ on 28.04 .2020 . The modified mathematical modeling estimation for the COVID-19 deaths started on 20.03.2020 because the number of deaths were then significant enough for estimation with the modified mathematical model. The estimation accuracy for the number of deaths was $100 \%$ with a value of 37 on 23 March 2020, and after that, it had always remained above $90 \%$ until 13.04.2020. Finally, it was $66.08 \%$ on 28.042020 . The estimation accuracies of the modified mathematical model about the COVID-19 cases in Turkey for 30 days and 45 days were above $90 \%$ and $78 \%$ respectively. The estimation accuracies of the modified mathematical model about the COVID19 deaths in Turkey for the 30-day and 45 -day periods were above $90 \%$ and $66 \%$, respectively. This result suggests that the modified mathematical model is available for estimating the course of disease outbreaks and pandemics. The model should be developed through future studies, which will improve its estimation accuracy.
\end{abstract}

Keywords: COVID-19, coronavirus, mathematical modeling, error evaluation, pandemic

\section{INTRODUCTION}

The Coronavirus Disease 2019 (COVID19) is caused by the new type of coronavirus, severe acute respiratory syndrome coronavirus-2 (SARS-CoV-2), emerged in China at the end of 2019 and spread all over the world in a very short time. The WHO declared COVID-19 a global pandemic due to its rapid spread and lack of effective vaccination, immunization and treatment [1]. The symptoms of COVID-19 are variable. Some patients are asymptomatic, and some patients have severe respiratory failure. The main symptoms are fever, cough, headache and fatigue. In addition to clinical symptoms, the main method for the disease's diagnosis is Real-time PCR.
Typical-ground glass opacity in CT especially on the lower and peripheral lobes and viral infection findings in laboratory test results are also helpful for the diagnosis of COVID-19 [2]. Precautions are very effective in determining the velocity of the course of the COVID-19 pandemic. Routinely exercising [3], eating healthy foods [4], general hygiene, hand hygiene and using personal protective equipment like masks to prevent contamination [5], maintaining physical distance measures [6] and stopping tobacco consumption are effective precautions [7].

The first COVID-19 cases in Turkey were reported in March 2020. After that, deaths caused by COVID-19 began to occur. 
Comparison of Estimated and Real COVID-19 Cases and Deaths

Table 1. Values of estimated and real COVID-19 cases and deviation for 45 days in Turkey

\begin{tabular}{|c|c|c|c|}
\hline Date & $\begin{array}{l}\text { Real Number } \\
\text { of Cases }\end{array}$ & $\begin{array}{c}\text { Estimated } \\
\text { Number of Cases }\end{array}$ & \% Deviation \\
\hline 15.03 .2020 & 18 & 18 & 0.00 \\
\hline 16.03 .2020 & 47 & 90 & 91.49 \\
\hline 17.03 .2020 & 98 & 175 & 78.57 \\
\hline 18.03 .2020 & 191 & 292 & 52.88 \\
\hline 19.03 .2020 & 359 & 449 & 25.07 \\
\hline 20.03 .2020 & 670 & 656 & -2.09 \\
\hline 21.03 .2020 & 947 & 923 & -2.53 \\
\hline 22.03 .2020 & 1236 & 1262 & 2.10 \\
\hline 23.03 .2020 & 1529 & 1686 & 10.27 \\
\hline 24.03 .2020 & 1872 & 2211 & 18.11 \\
\hline 25.03 .2020 & 2433 & 2853 & 17.26 \\
\hline 26.03 .2020 & 3629 & 3629 & $0.00 *$ \\
\hline 27.03 .2020 & 5698 & 5678 & -0.35 \\
\hline 28.03 .2020 & 7402 & 6949 & -6.12 \\
\hline 29.03 .2020 & 9217 & 8448 & -8.34 \\
\hline 30.03 .2020 & 10827 & 10171 & -6.06 \\
\hline 31.03 .2020 & 13531 & 12132 & -10.34 \\
\hline 1.04 .2020 & 15679 & 14339 & -8.55 \\
\hline 2.04 .2020 & 18135 & 16796 & -7.38 \\
\hline 3.04 .2020 & 20921 & 19502 & -6.78 \\
\hline 4.04 .2020 & 23934 & 22447 & -6.21 \\
\hline 5.04 .2020 & 27069 & 25615 & -5.37 \\
\hline 6.04 .2020 & 30217 & 28983 & -4.08 \\
\hline
\end{tabular}

There has been a great effort to control the COVID-19 pandemic both in Turkey and across the world. One of the most important stages in the fight against a pandemic is to simulate the course of the pandemic. The course of the COVID-19 pandemic in Turkey was previously estimated by us by using a mathematical model [8]. This study aimed to make a retrospective evaluation of forty-five days of COVID19 cases and deaths simulated by the modified mathematical model which was previously established and published by us.

\section{MATERIALS AND METHODS}

The modified mathematical modeling estimations which were performed by us were compared to the real numbers of the COVID- 19 cases and deaths in Turkey for 30-day and 45day periods since 15.03 .2020 , and the estimation accuracy was calculated. $[8,10]$.

\section{RESULTS}

The results of the modified mathematical modeling estimations and real COVID19 cases were compared, and the estimation accuracy was around $100 \%$ with a value of 3,629 on March 26, 2020. According to the modified mathematical modeling results on the COVID-19 cases after March 20, 2020, when the number of cases increased to a significant level, the estimation accuracy always remained above $90 \%$ until April 13, 2020. This rate was $78.40 \%$ on
Table 1 (continued). Values of estimated and real COVID-19 cases and deviation for 45 days in Turkey

\begin{tabular}{cccc}
\hline Date & $\begin{array}{c}\text { Real Number } \\
\text { of Cases }\end{array}$ & $\begin{array}{c}\text { Estimated } \\
\text { Number of Cases }\end{array}$ & \% Deviation \\
\hline 7.04 .2020 & 34109 & 32518 & -4.66 \\
\hline 8.04 .2020 & 38226 & 36186 & -5.34 \\
\hline 9.04 .2020 & 42282 & 39944 & -5.53 \\
\hline 10.04 .2020 & 47029 & 43750 & -6.97 \\
\hline 11.04 .2020 & 52167 & 47560 & -8.83 \\
\hline 12.04 .2020 & 56956 & 51330 & -9.88 \\
\hline 13.04 .2020 & 61049 & 55021 & -9.87 \\
\hline 14.04 .2020 & 65111 & 58598 & -10.00 \\
\hline 15.04 .2020 & 69392 & 62032 & -10.61 \\
\hline 16.04 .2020 & 74193 & 65299 & -11.99 \\
\hline 17.04 .2020 & 78546 & 68382 & -12.94 \\
\hline 18.04 .2020 & 82329 & 71296 & -13.40 \\
\hline 19.04 .2020 & 86306 & 73956 & -14.31 \\
\hline 20.04 .2020 & 90980 & 76441 & -15.98 \\
\hline 21.04 .2020 & 95591 & 78727 & -17.64 \\
\hline 22.04 .2020 & 98674 & 80821 & -18.09 \\
\hline 23.04 .2020 & 101790 & 82729 & -18.73 \\
\hline 24.04 .2020 & 104912 & 84464 & -19.49 \\
\hline 25.04 .2020 & 107773 & 86035 & -20.17 \\
\hline 26.04 .2020 & 110130 & 87454 & -20.59 \\
\hline 27.04 .2020 & 112261 & 88734 & -20.96 \\
\hline 28.04 .2020 & 114653 & 89886 & -21.60 \\
\hline & & & \\
\hline
\end{tabular}

April 28, 2020. The estimation accuracy values for the estimated and real 45-day COVID-19 cases that started from March 15, 2020 in Turkey are presented in Table $\mathbf{1}$ and Figure 1.

The modified mathematical modeling estimation for the COVID-19 deaths started on 20.03 .2020 because the number of deaths were then significant enough for estimation with the modified mathematical model. The estimation accuracy was $100 \%$ with a value of 37 on March 23, 2020. The estimation accuracy always remained above $90 \%$ until April 13,2020 , and it was $66.08 \%$ on April 28, 2020. The estimation accuracy values for the estimated and real 45 days of COVID-19 deaths that started from March 15, 2020 in Turkey are presented in Table $\mathbf{2}$ and Figure 2. 


\section{Graph of comparision between estimated and real COVID-19} cases in Turkey

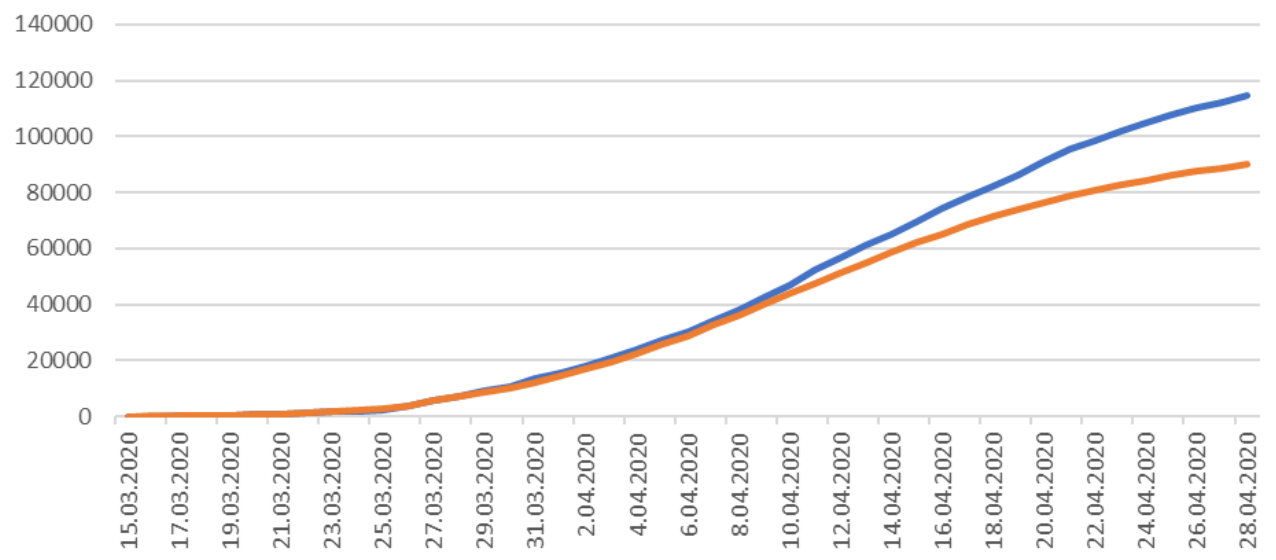

Real Number of Cases $\longrightarrow$ Estimated Number of Cases

Figure 1. Graph of comparison between estimated and real COVID-19 cases for 45 days in Turkey

Table 2. Values of estimated and real COVID-19 deaths and deviation for 45 days in Turkey

\begin{tabular}{cccc}
\hline Date & $\begin{array}{c}\text { Real Number } \\
\text { of Cases }\end{array}$ & $\begin{array}{c}\text { Estimated } \\
\text { Number of Cases }\end{array}$ & \% Deviation \\
\hline 15.03 .2020 & 0 & 0 & 0 \\
\hline 16.03 .2020 & 1 & 0 & -100.00 \\
\hline 17.03 .2020 & 2 & 0 & -100.00 \\
\hline 18.03 .2020 & 3 & 0 & -100.00 \\
\hline 19.03 .2020 & 4 & 0 & -100.00 \\
\hline 20.03 .2020 & 9 & 14 & 55.56 \\
\hline 21.03 .2020 & 21 & 20 & -4.76 \\
\hline 22.03 .2020 & 30 & 27 & -10.00 \\
\hline 23.03 .2020 & 37 & 37 & 0.00 \\
\hline 24.03 .2020 & 44 & 48 & 9.09 \\
\hline 25.03 .2020 & 59 & 62 & 5.08 \\
\hline 26.03 .2020 & 75 & 79 & 5.33 \\
\hline 27.03 .2020 & 92 & 124 & 34.78 \\
\hline 28.03 .2020 & 108 & 152 & 40.74 \\
\hline 29.03 .2020 & 131 & 185 & 41.22 \\
\hline 30.03 .2020 & 168 & 223 & 32.74 \\
\hline 31.03 .2020 & 214 & 266 & 24.30 \\
\hline 1.04 .2020 & 277 & 315 & 13.72 \\
\hline 2.04 .2020 & 356 & 369 & 3.65 \\
\hline 3.04 .2020 & 425 & 429 & 0.94 \\
\hline 4.04 .2020 & 501 & 493 & -1.60 \\
\hline 5.04 .2020 & 574 & 563 & -1.92 \\
\hline 6.04 .2020 & 649 & 637 & -1.85 \\
\hline & & & \\
\hline & 310 & 0 & 0 \\
\hline
\end{tabular}

\section{DISCUSSION}

The first COVID-19 cases in Turkey were reported in March 2020 and followed by COVID-19 deaths [10]. After that, serious measures had been taken to control and prevent the spread of the pandemic by the Turkish government. The
Table 2 (continued). Values of estimated and real COVID-19 deaths and deviation for 45 days in Turkey

\begin{tabular}{|c|c|c|c|}
\hline Date & $\begin{array}{l}\text { Real Number } \\
\text { of Cases }\end{array}$ & $\begin{array}{c}\text { Estimated } \\
\text { Number of Cases }\end{array}$ & \% Deviation \\
\hline 7.04 .2020 & 725 & 715 & -1.38 \\
\hline 8.04 .2020 & 812 & 796 & -1.97 \\
\hline 9.04 .2020 & 908 & 878 & -3.30 \\
\hline 10.04 .2020 & 1006 & 962 & -4.37 \\
\hline 11.04 .2020 & 1101 & 1046 & -5.00 \\
\hline 12.04 .2020 & 1198 & 1129 & -5.76 \\
\hline 13.04 .2020 & 1296 & 1210 & -6.64 \\
\hline 14.04 .2020 & 1403 & 1289 & -8.13 \\
\hline 15.04 .2020 & 1518 & 1364 & -10.14 \\
\hline 16.04 .2020 & 1643 & 1436 & -12.60 \\
\hline 17.04 .2020 & 1769 & 1504 & -14.98 \\
\hline 18.04 .2020 & 1890 & 1567 & -17.09 \\
\hline 19.04 .2020 & 2017 & 1627 & -19.34 \\
\hline 20.04 .2020 & 2140 & 1681 & -21.45 \\
\hline 21.04 .2020 & 2259 & 1732 & -23.33 \\
\hline 22.04 .2020 & 2376 & 1778 & -25.17 \\
\hline 23.04 .2020 & 2491 & 1820 & -26.94 \\
\hline 24.04 .2020 & 2600 & 1858 & -28.54 \\
\hline 25.04 .2020 & 2706 & 1892 & -30.08 \\
\hline 26.04 .2020 & 2805 & 1924 & -31.41 \\
\hline 27.04 .2020 & 2900 & 1952 & -32.69 \\
\hline 28.04 .2020 & 2992 & 1977 & -33.92 \\
\hline
\end{tabular}

intensity of measures had been changed with the number of cases and deaths by the government [11]. Therefore, it is important to estimate the number of the COVID-19 cases and deaths for a successful fight against the pandemic. The modified mathematical model that we established was helpful for simulating the COVID-19 cases and deaths [8]. 


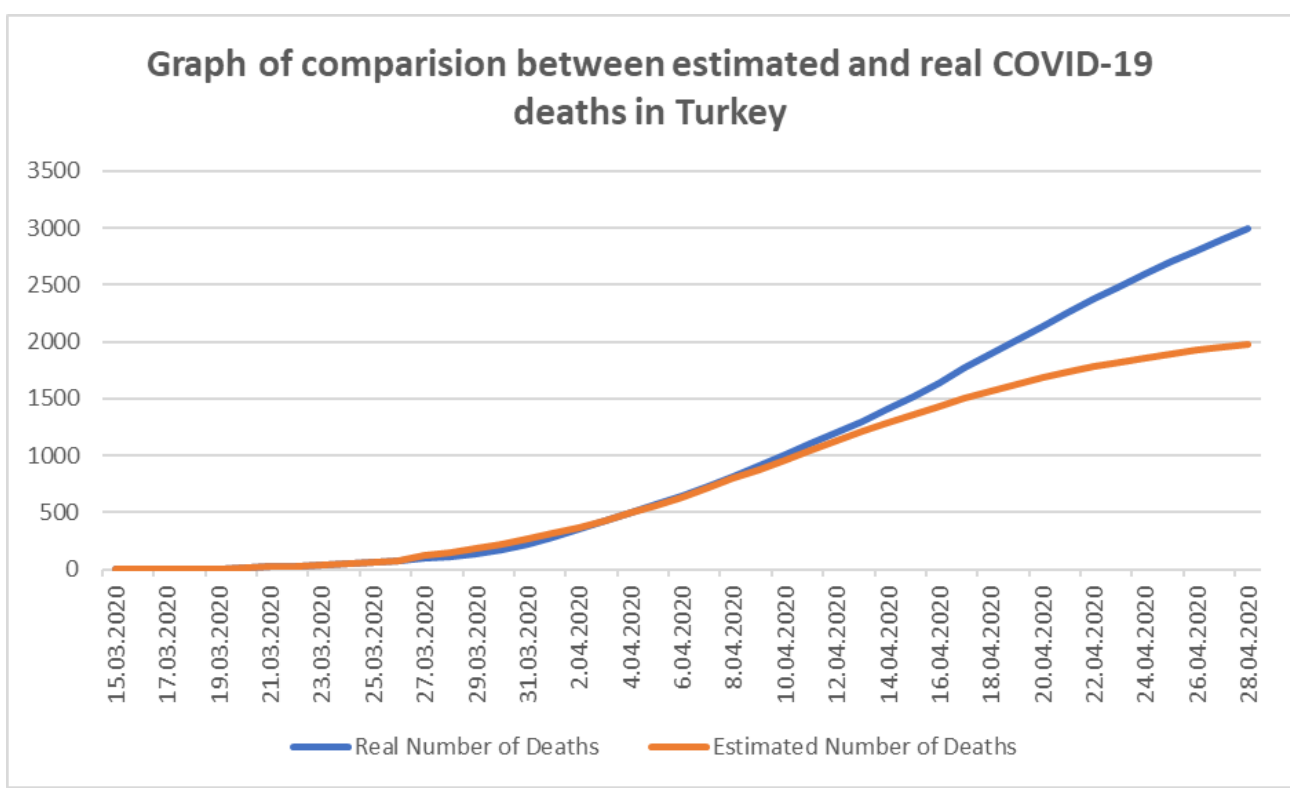

Figure 2. Graph of comparison between estimated and real COVID-19 deaths for 45 days in Turkey

When the number of the COVID-19 cases increased to a significant level on 20 March 2020, our modified mathematical modeling results' estimation accuracy remained above $90 \%$ until 13.04 .2020 . When the 45 days of modified mathematical modeling estimation accuracy were evaluated, it was seen that the estimation accuracy always remained above $78 \%$ until 28.04.2020. The modified mathematical modeling estimation accuracy values for 30 days and 45 days of the COVID-19 deaths in Turkey were above $90 \%$ and $66 \%$, respectively. This result suggested that the modified mathematical model that we established is a good choice for estimating the course of disease outbreaks and pandemics. The model should be developed further through future studies, which will improve its estimation accuracy $[9,10]$. The deviation of the modified mathematical modeling estimation accuracy was caused by the strict measures for controlling and preventing COVID-19 for the first 30 days following the first cases, but after the 30-day period, the compliance with these strict measures decreased. Modified mathematical model simulations for the course of epidemic diseases may be helpful for fighting plans against diseases.

Declaration of interest: The authors report no conflicts of interest.

Financial Disclosure: No financial support was received.

\section{REFERENCES}

1. Guo YR, Cao QD, Hong ZS, Tan YY, Chen SD, Jin HJ. The origin, transmission and clinical therapies on coronavirus disease 2019 (COVID-19) outbreak-an update on the status. Mil. Med. Res. 2020; 7(1): 1-10.

2. Pascarella G, Strumia A, Piliego C, Bruno F, Del Bueno R, Costa F, Scarlata S, Agro FE. COVID-19 diagnosis and management: a comprehensive review. J. Intern Med., 2020; 288(2): 192-206. doi: 10.1111/joim.13091.
3. Chen P, Mao L, Nassis GP, Harmer P, Ainsworth BE, Li F. Coronavirus disease (COVID-19): The need to maintain regular physical activity while taking precautions. J Sport Health Sci., 2020; 9(2): 103-4. doi: 10.1016/j.jshs.2020.02.001.

4. Butler MJ, Barrientos RM. The impact of nutrition on COVID-19 susceptibility and long-term consequences. Brain Behav Immun., 2020; 87: 53-4. doi: 10.1016/j.bbi.2020.04.040.

5. Guner R, Hasanoglu İ, Aktas F. COVID-19: Prevention and control measures in community. Turk J Med Sci., 2020; 50(3): 571-7. doi: 10.3906/sag-2004-146.

6. Jarvis CI, Zandvoort KV, Gimma A, Prem K, Klepac P, Rubin GJ, Edmunds WJ. Quantifying the impact of physical distance measures on the transmission of COVID-19 in the UK. Jarvis et al. BMC Medicine, 2020; 18(124): 1-10. doi: 10.1186/s12916-020-01597-8.

7. Vardavas CI, Nikitara K. COVID-19 and smoking: A systematic review of the evidence. Tob Induc Dis., 2020; 18(20): 1-4. doi: 10.18332/tid/119324.

8. Cakir Z, Savas HB. A Mathematical Modelling Approach in the Spread of the Novel 2019 Coronavirus SARS-CoV-2 (COVID-19) Pandemic. Electron J Gen Med., 2020; 17(4): em205. doi: 10.29333/ejgm/7861.

9. Cakir Z, Savas HB. A mathematical modelling for the COVID-19 pandemic in Iran. Ortadogu Med. J. 2020; 12(2): 206-10. doi: 10.21601/ortadogutipdergisi.715612.

10. Worldometers. Available at: https://www.worldometers. info/coronavirus/country/turkey/ (Accessed: 18 May 2020).

11. Demirbilek Y, Pehlibanturk G, Ozguler ZÖ, Alp ME. COVID-19 outbreak control, example of ministry of health of Turkey. Turk J. Med. Sci., 2020; 50(3): 489-94. doi: 10.3906/sag-2004-187. 